\title{
EDUKASI MANFAAT ASI EKSKLUSIF KEPADA KADER KESEHATAN DAN IBU BALITA DI DESA WOWA TAMBOLI
}

\section{EDUCATION ABOUT BENEFITS OF EXCLUSIVE BREAST MILK TO HEALTH CARE AND MOTHER OF CHILDREN IN WOWA TAMBOLI VILLAGE}

\author{
Yuhanah $^{1)}$, Grace Tedy Tulak ${ }^{2)^{*}}$ \\ ${ }^{1)}$ Fakultas Sains dan Teknologi, Universitas Sembilanbelas November Kolaka \\ email: yuhanah12764@gmail.com \\ ${ }^{2)}$ Fakultas Sains dan Teknologi, Universitas Sembilanbelas November Kolaka \\ email: gracelavianni@gmail.com
}

\begin{abstract}
ABSTRAK
ASI eksklusif merupakan nutrisi yang paling tepat diberikan kepada bayi baru lahir hingga usia 6 bulan. ASI eksklusif dapat memperbaiki status nutrisi pada bayi serta meminimalkan angka kesakitan dan kematian pada bayi. Salah satu cara mensukseskan pemberian ASI eksklusif dengan melaksanakan penyuluhan kepada kader kesehatan dan ibu yang memiliki balita. Kader kesehatan merupakan orang yang sering bersosialisasi dengan masyarakat dalam menyampaikan informasi terkait dengan kesehatan. Tujuan kegiatan pengabdian kepada masyarakat ini dilaksanakan untuk meningkatkan pengetahuan dan kesadaran kader kesehatan dan ibu balita tentang manfaaat ASI eksklusif dalam mendukung program pemerintah tentang peningkatan cakupan pemberian ASI eksklusif . Program ini dilaksanakan pada tanggal 25 Januari 2020 dalam bentuk penyuluhan kesehatan kepada kader kesehatan dan ibu balita dengan jumlah peserta sebanyak 75 orang. dengan mengajukan pertanyaan pada sesi diskusi. Dosen pengabdi mengharapkan partisipasi kader kesehatan untuk melakukan pendampingan kepada ibu hamil dan menyusui dalam rangka meningkatkan cakupan ASI eksklusif.
\end{abstract}

Kata kunci: ASI eksklusif, Edukasi, Kader kesehatan, Ibu balita, Wowa Tamboli

\section{ABSTRACT}

Exclusive breastfeeding is the most appropriate nutrition given to newborns up to the age of 6 months. Exclusive breastfeeding can improve nutritional status in infants and minimize morbidity and mortality in infants. One way to succeed in giving exclusive breastfeeding is by conducting counseling to health cadres and mothers who have toddlers. Health cadres are people who often socialize with the community in delivering information related to health. The purpose of community service activities is carried out to increase the knowledge and awareness of health cadres and mothers of children under five about the benefits of exclusive breastfeeding in supporting government programs on increasing the scope of exclusive breastfeeding. The program was carried out on January 25, 2020 in the form of health education to health cadres and mothers of children under five with 75 participants. The extension participants were very enthusiastic about the activity and gave feedback by asking questions in the discussion session. Dedicated lecturers expect the participation of health cadres to provide assistance to pregnant and lactating women in order to increase coverage of exclusive breastfeeding.

Keywords: Exclusive breastfeeding, Education, Health care, Mother of children, Wowa tamboli

\section{PENDAHULUAN}

Pemberian ASI eksklusif merupakan

program pemerintah yang diatur dalam peraturan

pemerintah Republik Indonesia no 33 tahun

2012 dan merupakan program prioritas oleh

karena memberikan dampak yang luas pada satus gizi dan kesehatan balita. Program ini juga

direkomendasikan oleh WHO dan UNICEF.

Pemberian ASI eksklusif dimulai setelah bayi

lahir sampai usia 6 bulan dan setelah 6 bulan

diberikan makanan/minuman pendamping 
namun ASI tetap diberikan hingga usia 2 tahun atau lebih [1].

Nutrisi yang diperoleh sejak bayi lahir tentunya sangat berpengaruh terhadap pertumbuhannya termasuk resiko terjadinya stunting. Tidak terlaksananya inisiasi menyusu dini (IMD), gagalnya pemberian ASI eksklusif serta proses penyapihan dini merupakan faktor pencetus stunting. Cakupan bayi yang mendapatkan ASI eksklusif secara nasional pada tahun 2017 sebesar 61,33 \%, persentase tertinggi terdapat di Nusa Tenggara Barat sebesar $87,35 \%$ dan persentase terendah terdapat di Papua (15,32\%) sedangkan presentase di Sulawesi Tenggara sebesar 64,05 \%. Masih terdapat 19 provinsi yang berada di bawah angka nasional, oleh karena itu sosialisasi tentang manfaat dan pentingnya ASI eksklusif masih perlu ditingkatkan [2].

Pengetahuan ibu tentang ASI eksklusif memegang peranan yang besar terhadap keberhasilan pemberian ASI eksklusif. Pengetahuan merupakan hasil dari tahu dan terjadi setelah seseorang melakukan penginderaan terhadap objek tertentu baik melalui indera penglihatan, rasa, pencimuan, pendengaran dan raba. Namun sebagian besar pengetahuan diperoleh dari indera penglihatan dan pendengaran [3]. Hasil penelitian memperlihatkan bahwa ibu tahu dan mengerti tentang ASI eksklusif namun tidak memberikan ASI secara eksklusif pada anaknya. Hal ini terjadi karena kurangnya pemahaman tentang praktik menyusui yang baik dan benar [4].

Kader posyandu juga memegang peranan penting dalam peningkatan cakupan ASI eksklusif. Kader posyandu merupakan anggota masyarakat yang memiliki kemampuan dan komitmen menyelenggarakan, bersedia diberikan pendidikan dan pelatihan untuk ikut andil dalam penyelenggaraan posyandu [5]. Kader yang memiliki pengetahuan yang baik dapat memberikan informasi yang baik kepada masyarakat guna mensukseskan program pemerintah. Salah satu upaya yang dapat dilakukan untuk meningkatkan pengetahuan kader melalui penyuluhan kesehatan. Sebuah studi menunjukkan adanya peningkatan pengetahuan kader tentang ASI eksklusif setelah diberikan penyuluhan dan pendampingan [6].

Hasil pencatatan cakupan ASI eksklusif di Puskesmas Tosiba pada tahun 2019 sebanyak 60 $\%$ dari target $100 \%$ Presentase ini menunjukkan masih rendahnya cakupan ASI eksklusif dan menjadimasalah yang harus diperhatikan. Kurangnya informasi yang diterima oleh ibu ataupun kurangnya kesadaran ibu memberikan ASI eksklusif menjadi faktor pencetusnya. Hasil wawancara awal dengan kader kesehatan mengatakan bahwa kegiatan penyuluhan tentang ASI eksklusif masih kurang dilaksanakan sehingga cakupannya masih belum mencapai target. Hal ini mendorong dosen pengabdi untuk melaksanakan kegiatan peningkatan pengetahuan melalui penyuluhan tentang manfaat ASI eksklusif kepada kader kesehatan dan ibu balita.

\section{METODE PELAKSANAAN KEGIATAN}

Dosen pelaksana kegiatan pengabdian kepada masyarakat menggunakan metode penyuluhan menggunakan media $L C D$ dan 
flipchart yang berisi materi tentang manfaat ASI eksklusif pada bayi. Puskesmas Tosiba sebagai mitra kegiatan ini berperan secara aktif baik sebagai subjek maupun objek kegiatan ini. Pelaksanaan kegiatan disepakati pada tanggal 25 Januari 2020 bertempat di balai desa, poskesdes dan kelompok dasawisma.

Tahap awal kegiatan ini dilaksanakan dengan melakukan survey dan diskusi, puskesmas sebagai mitra menjadi sumber data dan menetapkan waktu pelaksanaan kegiatan. Pada saat pelaksanaan kegiatan, dosen pengabdi berperan sebagai subjek sedangkan kader kesehatan dan ibu balita sebagai objek transfer of knowledge. Kegiatan ini diikuti oleh 75 orang kader kesehatan dan ibu balita di desa Wowa Tamboli.

\section{HASIL DAN PEMBAHASAN}

Puskesmas Tosiba merupakan salah satu puskesmas rawat inap yang berkedudukan di Kabupaten Kolaka. Pencatatan puskesmas Tosiba tentang cakupan ASI ekslusif pada tahun 2019 sebesar $60 \%$.

Kegiatan pengabdian masyarakat dalam bentuk penyuluhan kesehatan dilaksanakan pada tanggal 20 Januari 2020 pukul 09.00-16.45 yang bertempat di 3 lokasi yakni balai desa Wowa, Poskeskes dan perkumpulan dasa wisma.

Tahap pelaksanaan kegiatan penyuluhan tentang manfaat ASI ekskluif digambarkan sebagai berikut :

1. Tahap Persiapan

a. Pengurusan ijin pelaksanaan kegiatan pengabdian dari LP2M-PMP Universitas Sembilanbelas November Kolaka. Setelah mendapatkan surat rekomendasi kegiatan dilanjutkan dengan pengurusan ijin ke Puskesmas sekaligus merencanakan waktu dan tempat pelaksanaan kegiatan serta jumlah peserta yang akan hadir dalam penyuluhan.

b. Pembuatan power point dan flipchart sebagai media penyuluhan

c. Pembuatan spanduk

d. Persiapan konsumsi peserta

e. Koordinasi dengan pihak terkait seperti kepala desa, kader kesehatan maupun ketua PKK

2. Tahap Pelaksanaan

a. Persiapan peserta

Peserta penyuluhan adalah kader PKK, kader posyandu, kader kesehatan dan ibu balita di desa Wowa Tamboli sebanyak 75 orang. Kegiatan ini juga dihadiri oleh pihak Puskesmas Tosiba dan ketua PKK desa Wowa Tamboli.

b. Proses penyuluhan

Kegiatan penyuluhan dilaksanakan di 3 lokasi sebagai berikut :

1) Balai desa Wowa Tamboli

Kegiatan penyuluhan di balai desa berlangsung pukul $09.00 \quad-11.15$ WITA yang dihadiri oleh 40 orang peserta (Gambar 1).

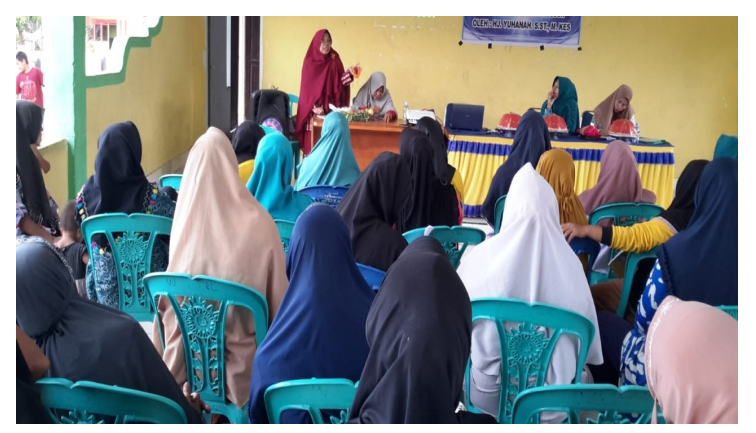

Gambar 1. Penyuluhan di Balai Desa 
2) Poskesdes

Kegiatan penyuluhan di Poskesdes berlangsung pukul 13.00-14.30 WITA dengan jumlah peserta sebanyak 20 orang (Gambar 2).

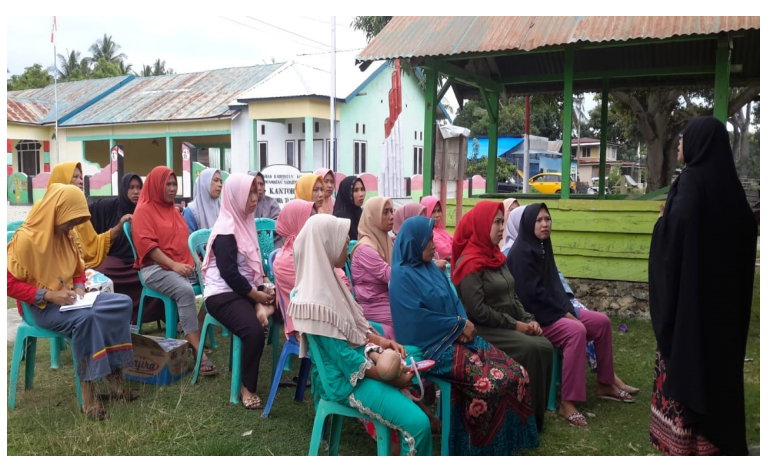

Gambar 2 Penyuluhan di Poskesdes

3) Perkumpulan Dasawisma Pesisir Pantai Kegiatan penyuluhan kepada dasawisma di pesisir pantai dilaksanakan pukul 15.00-16.45 WITA yang dihadiri oleh 15 orang peserta (Gambar 3).

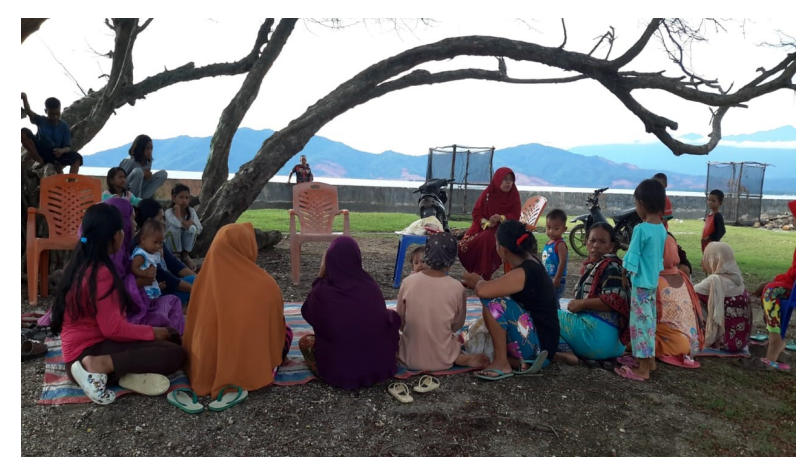

Gambar 3 Penyuluhan di Pesisir Pantai

Kader kesehatan dipilih dari dan oleh masyarakat melalui musyawarah yang bertugas melakukan penyuluhan kepada warga masyarakat untuk meningkatkan pengetahuan tentang kesehatan. Peran kader kepada ibu nifas dan ibu menyusui adalah memberikan pesan tentang pemberian ASI eksklusif dan tetap memberikan Asi sampai anak berusia 2 tahun [5].
Penyuluhan kesehatan dilakukan kepada kader kesehatan untuk meningkatkan pengetahuan tentang manfaat ASI eksklusif. Sebuah studi menjelaskan bahwa tingkat pengetahuan kader posyandu setelah dilakukan workhsop ASI eksklusif mengalami peningkatan menjadi $100 \%$ [7].

Kegagalan pemberian ASI eksklusif disebabkan oleh kurangnya pengetahuan ibu yang dapat diatasi dengan penyuluhan kesehatan. Ibu yang memiliki pengetahuan yang rendah tentang ASI eksklusif cenderung tidak memberikan ASI eksklusif pada bayinya. Pengetahuan tentang cara menyusui yang baik dan benar menjadi faktor pendukungnya [8].

3. Tahap Evaluasi

Hasil evaluasi pelaksanaan kegiatan ini digambarkan sebagai berikut :

a. Peserta yang hadir mengikuti kegiatan dengan baik sampai selesai bahkan terdapat peserta yang hadir dengan membawa anak

b. Pada saat sesi diskusi terdapat ibu yang bertanya terkait pemberian ASI eksklusif.

1) “Apakah proses menyusui tetap dilanjutkan apabila kondisi payudara sedang bengkak?"

2) "Bagaimana dengan ibu yang tidak memiliki puting susu? Apakah ada solusi yang bisa diberikan agar pemberian ASI eksklusif tetap terlaksana?"

3) "Bagaimana jika ibu dalam kondisi sakit, apakah masih bisa menyusui bayinya?" 
4. Hambatan dan Kendala

Sulitnya mengumpulkan peserta dalam satu lokasi untuk pelaksanaan kegiatan merupakan salah satu kendala yang dihadapi dalam pelaksaan kegiatan ini. Jarak rumah dengan balai desa yang cukup jauh menjadi salah satu penyebabnya. Solusi yang dilakukan dengan melaksanakan penyuluhan dalam 3 lokasi yakni balai desa, poskesdes dan perkumpulan dasawisma pesisir pantai.

Tidak tersedianya ruangan pertemuan di poskesdes dan pesisir pantai menyebabkan kegiatan penyuluhan dilaksanakan di halaman poskeskes dan di halaman rumah warga masyarakat.

\section{Kekuatan}

Respon yang kuat dari pihak Puskesmas Tosiba, kepala desa dan ketua PKK menjadi kekuatan dalam pelaksanaan kegiatan ini. Tingginya minat masyarakat terhadap kesehatan menyebabkan acara ini dapat berlangsung sesuai dengan rencana.

\section{KESIMPULAN}

Kegiatan pengabdian kepada masyarakat melalui penyuluhan kesehatan untuk meningkatkan pengetahuan kader dan ibu balita tentang manfaat ASI eksklusif dihadiri oleh 75 orang yang berlangsung di 3 lokasi yakni balai desa, poskesdes dan perkumpulan dasawisma pesisir pantai.

Peserta dengan antusias mengikuti kegiatan dengan baik hingga selesai dan pada sesi diskusi peserta dengan aktif memberikan pertanyaan sekaligus berbagi pengalaman mengenai pemberian ASI yang selama ini mereka lakukan.
Kegiatan ini diharapakan dapat mendorong kader untuk lebih giat melakukan sosialisasi dan pendampingan $\mathrm{ibu}$ dalam pemberian ASI eksklusif. Diharapkan kepada ibu balita agar dapat mengimplementasikan pemberian ASI eksklusif demi kesehatan bayi dan mendukung program pemerintah dalam peningkatan cakupan ASI eksklusif.

\section{SARAN}

1. Diharapkan kepada pihak puskesmas untuk melakukan kegiatan pendampingan pemberian ASI eksklusif bagi ibu yang memiliki bayi di wilayah kerja Puskesmas Tosiba

2. Kader kesehatan lebih maksimal untuk melakukan sosialisasi ASI eksklusif kepada ibu hamil maupun ibu yang memiliki bayi.

\section{UCAPAN TERIMAKASIH}

1. Ketua

LP2M-PMP

Universitas

Sembilanbelas November yang telah memberikan rekomendasi pelaksanaan kegiatan ini.

2. Kepala Puskesmas Tosiba, kepala Desa Wowa Tamboli dan Ketua PKK yang telah memfasilitasi pelaksanaan kegiatan ini.

3. Kepada seluruh peserta yang telah meluangkan waktu untuk hadir dalam kegiatan ini.

\section{REFERENSI}

[1] Diyah Yuistika Handayani, H.D.A. 2015. Pemberdayaan kader posyandu dalam program ASI ekaklusif di desa Pamijen, Sokaraja, Banyumas. Jurnal ilmiah ilmuilmu kesehatan "MEDISAINS", 13(1)

[2] Kementerian Kesehatan RI. (2018). Situasi Balita Pendek (Stunting) di Indonesia.

[3] Notoatmodjo (2010) Ilmu Perilaku Kesehatan. Jakarta: Rineka Cipta

[4] Friya I., Maramis., Marjes Tamurang., 
A.F.K. 2017. Peran petugas promosi kesehatan, pengetahuan ibu dan dukungan keluarga dalam meningkatkan pemberian ASI eksklusif di wilayah kerja Puskesmas Airmadidi Kabupaten Minahasa Utara. Fakultas Kesehatan Masyarakat Universitas Sam Ratulangi Manado.

[5] Kementrian Kesehatan RI. 2012. Ayo ke Posyandu Setiap Bulan. Kementrian Kesehatan RI Pusat Promosi Kesehatan.

[6] Herlina, Rokhaidah, I.P. 2019. Penyuluhan dan pendampingan kader ASI eksklusif di Sawangan Depok Jawa Barat. "ABDAMAS"
Fakultas Ilmu Kesehatan Universitas Pembangunan Nasional "Veteran" Jakarta. 1, pp. 212-217

[7] Aprilina, Dwi Happy, et.al. 2017. Pengaruh workshop ASI eksklusif pada kader posyandu balita terhadap pengetahuan di desa Sokaraja Tengah, Banyumas. Jurnal Keperawatan Soedirman, 12(2):118-126

[8] Handayani, L., et al. 2016. The Association Between Breastfeeding Technique and Knowledge with Exclusive Breastfeeding, Indonesia Journal of Medicine and Health, 7(5):214-218 